\title{
How Do Customers Respond to Robotic Service? A Scenario-Based Study from the Perspective of Uncertainty Reduction Theory
}

\author{
Yanqing Lin \\ Aalto University School of Business \\ yanqing.lin@aalto.fi
}

\author{
Xun Zhou \\ Technical University of Munich \\ xun.zhou@tum.de
}

\author{
Wenjie Fan \\ Aalto University School of Business \\ wenjie.fan@aalto.fi
}

\begin{abstract}
Confronted with an increasing popularization and advancement of applying artificial intelligence in robotic technology, practitioners in the service sector have been increasingly deploying service robots in their operations. Motivated by a paucity of knowledge on how consumers would respond to the robotic service, this study establishes on the uncertainty reduction theory to advance a research model that seeks to unveil how both customer trait and service characteristic affect customers' revisit intention to robotic service via perceived risk. Based on a scenario-based experiment with 190 responses in the hotel reception service context, our results reveal that perceived risk partially mediates the relationship between personal innovativeness and service revisit intention, so does between service heterogeneity and revisit intention. Furthermore, the service context, i.e., whether the prior service experience satisfies the customer, can moderate the relationship between personal innovativeness (service heterogeneity) and perceived risk. This study also draws related theoretical and practical implications.
\end{abstract}

\section{Introduction}

The incorporation of artificial intelligence (AI) into the service sector finds expression in service robots' deployment. The proliferation and advancement of robotics have boosted the drive to replace humans with robots in the service sector, especially in tourism and hospitality [1], [2]. Concretely, there is an increasing trend that service robots come forward to the realms of hospitality operations, such as the services reception, delivery, and in-room companion [1], [3]. Under this circumstance, it is essential to figure out how customers respond to service robots' deployment and what outcome will result. However, there is a paucity of literature addressing this research question.
This study seeks to understand customers' response to robotic service from the lens of uncertainty reduction theory (URT). URT offers accounts for information-seeking strategies facing uncertainty [4], which allows explicating the role of both customer trait (personal innovativeness) and service characteristic (service heterogeneity) in robotic service adoption. In the context of URT, the subject (either an individual or an organization), while experiencing uncertainty, is motivated or driven to seek information to reduce uncertainty.

Personal innovativeness is conceptualized as an individual trait that reflects one's willingness to try new technology [5] and individual tolerance of risk [6]. Thus, personal innovativeness can be seen as a channel of uncertainty reduction, with considerable attention having been paid to the influence of personal innovativeness on innovation adoption [7], [8]. The service robot is a comparatively novel concept compared with human counterparts in the hospitality industry, bringing more uncertainty. In this line, increased personal innovativeness, which translated into promoted individual competence to cope with innovations, can be argued as a strategy for mitigating uncertainty and perceived risk. Therefore, it is worthwhile to examine the impact of personal innovativeness on robotic service adoption.

Heterogeneity is one of the four fundamental characteristics that distinguish services from tangible products, together with intangibility, simultaneity, and perishability [9]. Service heterogeneity refers to an attributive characteristic of service that arises from variability concerning service providers, customers, service times, or service sites [10]. Heterogeneity suggests that all service performance is somewhat different [11], and customers can expect future delivered service depending on the degree of perceived service heterogeneity [12]. In this vein, service heterogeneity can be viewed as an external cue that affects customers' uncertainty and behavioral outcomes. While previous studies allude to the importance of service heterogeneity in understanding customers' 
perceptions and service experience [10], [13], little is known about its effects in the context of robotic service. This study investigates customers' responding process to the service delivered by robots by explaining the role of personal innovativeness and service heterogeneity based on URT.

Apart from customer and service characteristics, whether the previous service experience is satisfied can also influence customers' perceptions [14]. This study argues that customers' perception of service robots is contingent on prior service experience (satisfied or dissatisfied). Therefore, this study explores how customers' perceptions derived from customer and service characteristics differ under the respective conditions of having a satisfying or dissatisfying prior service experience.

\section{Theoretical Foundation}

\subsection{Personal innovativeness}

In consumer psychological literature, personal innovativeness refers to a generalized individual personality trait that links to one's competence to accept innovations [15]. Following Roger [16], personal innovativeness is defined as an individual predisposed tendency toward adopting innovation, and individuals behave variously toward any new service or goods on account of their variability in innovative character.

Notably, previous studies have identified personal innovativeness as one of the significant determinants of the adoption and diffusion of innovative technologies [16], [17]. Several scholars have found evidence that personal innovativeness significantly contributes to the adoption of either new products or services [18], [19]. For instance, Im et al. [20] view personal innovativeness as a kind of higher-order personality trait, which exerts both direct and indirect effects on new product adoption. Further, personal innovativeness has also been identified as a critical construct in online shopping adoption and significantly associated with increased online shopping intention [21]. Yet, little is known when applying personal innovativeness in the context of robotic service or the effect of personal innovativeness on robotic service adoption.

\subsection{Service heterogeneity}

Service heterogeneity, also dubbed service variability, concerns "the potential for high variability in the performance of services" [22, p. 124]. Service heterogeneity arises when different individuals are involved in service delivery [10], which is more so for more labor-intensive service [23]. Past studies imply that service delivery's heterogeneity mainly derives from the variability of the service providers [23], [24], because different service providers have different personalities, service delivery skills, and attitudes to customers, to name but a few [24]. Moreover, even the same service provider might deliver differentiated service performance.

According to a systematic literature review of 46 academic articles, heterogeneity in service acts as a significant conceptual notion for understanding customer perception and service adoption. Heterogeneity can induce a feeling of uncertainty [25], which is one of the main antecedents of perceived risk [26]. In this vein, a higher level of service heterogeneity may increase customers' perceived risk of the received service, which in turn can deteriorate purchase intention for services [27]. Several studies offer empirical support for this assertion. For example, Roy \& Sivakumar [10] convey that heterogeneity in service enables one to have negative implications for customer experience, which might further contribute to negative perceptions. The work of Agudo-Peregrina et al. [28] demonstrates that, in the context of online service, customers prefer homogeneous service to heterogeneous service because customers receiving homogeneous service have lower perceived risk and thus higher intention to purchase the service.

Although the conceptualization of heterogeneity has been well documented in service science, few studies have discussed service heterogeneity and its effects in the novel context of robotic service. Accordingly, this study aims to explore customers' response to robotic service through the lens of service heterogeneity in service encounters.

\subsection{Uncertainty reduction theory}

Uncertainty reduction theory (URT) suggests that, during the initial interactions, the primary concern of individuals is to reduce uncertainty about the interaction behavior between the individuals and their partners [4][29]. To minimize uncertainty and maximize predictivity, there are three general categories of information-seeking strategies in URT, including passive, active, and interactive strategies [30]. The passive strategy for an individual is to obtain information involving the target partners via unobtrusively observing their behaviors. In contrast, the active strategy is to proactively obtain information about the target partners from third parties or the environment. The interactive strategy, however, involves directly seeking information through confronting the target partners, such as direct interaction or interrogation. In 
summary, uncertainty reduction is primarily bent on seeking or gathering relevant information to increase predictability and decrease the perceived risk of outcomes.

Despite uncertainty reduction originating from the interpersonal communication field, URT has also been adopted as an underlying theory in consumer behavior. For instance, Shin et al. [31] find that both interactive and passive uncertainty strategies positively and significantly contribute to continuous visiting social networking behavior through the mediator of a low level of uncertainty. Venkatesh et al. [32] verify that both information quality and channel characteristics predict citizens' intentions to use egovernment via drawing from URT. Similarly, in the setting of online shopping, Racherla et al. [33] provide evidence that product reviews with either argument quality or perceived similarity contribute to increased customers' trust.

However, intangible services are perceived to be riskier than tangible products [34], considering the four above mentioned characteristics differentiating services from products [9]. As a result, customers tend to seek relevant information to reduce the uncertainty concerning services [34]. They utilize both external (such as environmental information [32]) and internal (such as prior service experience [35]) sources to acquire information and reduce the uncertainty of delivered service. Accordingly, in the context of robotic service, this study contends that the origin of perceived risk (dominantly arising from uncertainty) is anchored in both parties of service robots and customers. Therefore, customers' perception of the coming service encounter relies highly on individual competence, robotic service characteristics, and prior service experience. Nevertheless, few studies have employed the uncertainty reduction theory to explore how customers respond to robotic service. Guided by URT, this study examines the relationship between personal innovativeness (as well as service heterogeneity) and service revisit intention through the mediating effect of perceived risk.

\section{Hypotheses Development}

Individuals with higher innovativeness are more likely to adopt innovations earlier than others [36]. Although numerous factors, such as knowledge and exposure to technologies, contribute to the development of personal innovativeness, individuals' willingness to adopt uncertainty and their risk-taking ability are most significant for being innovators and early adopters [36]. Past studies have identified the positive role of personal innovativeness in technology adoption and risk perception reduction in various contexts of, for example, telephone shopping [37], online banking services [19], [38], and online shopping [21].

As a novel expression of AI technology, robotic service brings customers an innovative form of service delivery, which may trigger a feeling of uncertainty [39]; uncertainty is one of the significant precursors of risk perception cultivation [26], [40]. Following URT, it is conceivable that people with a higher competence to cope with uncertainties tend to have lower risk perception. Even in situations where service robots failed to perform successful services, customers with greater innovativeness can be more competent to deal with service failure and perceive lower risk. Thus, we hypothesize that:

H1: Personal innovativeness negatively associates with perceived risk.

Service failure is inevitable during service delivery, especially in tourism and hospitality [41]. Given the possibility of mechanical malfunctions and customer misoperations, service failure is also likely to occur in robotic service. In particular, since service robots' deployment is at the very initial stage nowadays, robots are still directional to delivering inconsistent service.

Past studies suggest that service heterogeneity enables customers to predict the service they are likely to receive [12]. The higher heterogeneity in the provision of service, the more difficult it will be for customers to predict the service quality they are going to receive, since higher service heterogeneity conveys more variability and uncertainties in the service per se [25]. Considering the positive association between uncertainty and perceived risk [26], [40], more heterogeneous service can trigger more uncertainties about the service that customers are likely to experience, leading to higher risk perception. Thus, we hypothesize that:

H2: Service heterogeneity positively associates with perceived risk.

The sources of risk perception include such two dimensions as uncertainty and adverse consequences of the receiving innovations [40]. Customers' risk perception acts as a primary obstacle to adopt innovations, including products, services, and ideas [19]. Findings across different research contexts suggest the negative effect of perceived risk on adoption intention. For instance, as demonstrated in the case of tangible goods, past studies have found that perceived risk significantly decreases customers' willingness to purchase online [21]. A similar conclusion about the negative effect of perceived risk on consumers' service adoption has also been drawn in online banking services [19], [38] and tourism [42]. In this line, if customers have a higher risk perception 
for the service delivery, they are less willing to adopt the robotic service, reflecting on reduced intention to re-patronize the service. Thus, we hypothesize that:

H3: Perceived risk negatively associates with service revisit intention.

The previous service performance acts as a significant basis to predict future service performance [43]. Either successful or unsuccessful service may happen in the robotic service. When the service robot has already delivered favorable service, there is a high possibility that it will consistently satisfy the customer in the future service because robots behave under pre-designed patterns. In such a situation, customers' risk perception may be reduced, and the alleviating effect of personal innovativeness on perceived risk can be strengthened. Contrarily, when a service failure occurs, given the relative inflexibility and consistency of robotic service, the customer would expect to receive consistently unfavorable service next time, thereby perceiving higher risk. This may weaken customers' confidence in experiencing satisfying service next time even if they have high risk-taking competence. Thus, we posit:

H4: Service context moderates the relationship between personal innovativeness and perceived risk.

In view of the inevitability of service failure during service delivery [41] and the significance of service heterogeneity in service prediction [12], we assume that the relationship between service heterogeneity and perceived risk is contingent on the prior robotic service performance. When customers received satisfying service, higher service heterogeneity conveys more uncertainties and a higher likelihood to receive future service differing from the previously satisfying one, thereby strengthening their risk perception. On the flip side, it is reasonable for the dissatisfied customer to infer that greater service heterogeneity makes the next delivery service greatly different from the prior unsatisfactory service, that is, more likely to be favorable. This inference, therefore, reduces customers' perceived risk. Thus, we posit:

H5: Service context moderates the relationship between service heterogeneity and perceived risk.

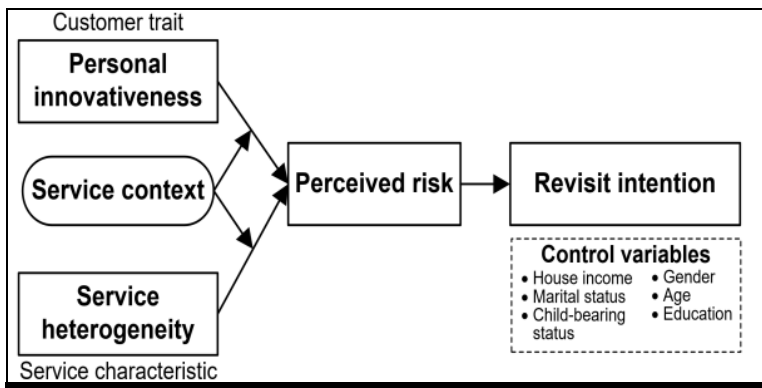

Figure 1. Research Model
Following previous studies [12], [44], this study covers several control variables in the research model to ensure the robustness of data analysis (see Figure $1)$.

\section{Methodology}

This study employs a scenario-based experiment to verify the proposed research model. The scenariobased design has been extensively used in the information system (IS) research [45]. The scenario is conceptualized as a situation description that assumes to happen in the potential future, having been widely employed in experimental studies that need to manipulate various conditions of variables, simulate response tasks, or represent a research context [46]. With a scenario-based experiment, a participant is first required to carefully go through one or more scenarios that contain a subset of the experimental treatments; and then respond to a survey based on their perceptions of each scenario.

\subsection{Study design}

4.1.1 Scenario setting. Given the increasing deployment of service robots in hospitality and representativeness of robot bellhops in reception service [3], this study singles out hotel robot receptionists as research objects. To create qualified scenarios, we first studied all the available Tripadvisor reviews of Hennna Hotel in Japan $(N=162$, Retrieved January 8, 2020), which is the first hotel using service robots in its entire service operational process from 2015. Using both positive and negative reviews related to the robot receptionist, we set up two scenarios reflecting the actual successful and unsuccessful performance of robot receptionists.

Since "context defines the conditions experienced by the users" [47, p. 352], the service condition experienced by the customer is termed as "service context". The satisfying service context (Scenario I) and dissatisfying service context (Scenario II) refer to where customers use robot receptionists successfully and unsuccessfully, respectively. For the robustness of the created scenarios, an expert review panel consisting of four IS researchers was convened for assessing each scenario's realism and validity [48]. Based on the panel's feedback, improvement for the scenarios' description was made to enhance its reliability and reduce overall ambiguity [49]. The final scenario descriptions can be found in Supplementary Materials.

4.1.2 Measurement. Considering that few suitable measurements of service heterogeneity are available, 
we self-created eight measurement items for service heterogeneity following the recommended procedure in previous studies [50], [51] (See Supplementary Materials). Measurement scales for the other three constructs, i.e., personal innovativeness [17], [52], perceived risk [53], [54], and revisit intention [55] were adopted from the previous literature. To guarantee adequate reliability and validity of these constructs, we conducted a pre-test with 60 respondents and improved the survey based on their feedback.

\subsection{Data collection}

All the respondents are from Amazon Mechanical Turk (MTurk). Those who completed the experiment would receive one USD as compensation. As Figure 2 illustrates, once completing a consent statement, participants would be asked about their experiences with hotel services. Those without any hotel accommodation experience in the past 12 months were excluded from this study. Then, participants needed to watch a one-minute video about how a robot receptionist works at the front desk (See Supplementary Materials), following which they were required to answer two questions about the video content to ensure they earnestly watched the video. Those who failed to offer correct answers would be excluded. Subsequently, the remaining participants were randomly assigned to one of the two created scenario descriptions. After reading the scenario description, they were asked to respond to two attention-check questions about the scenario description to guarantee they correctly understood the distributed scenario. Those who failed to pass the attentioncheck were excluded from the study. Note that participants who did not pass the attention-check embedded in the survey questions were also dropped.

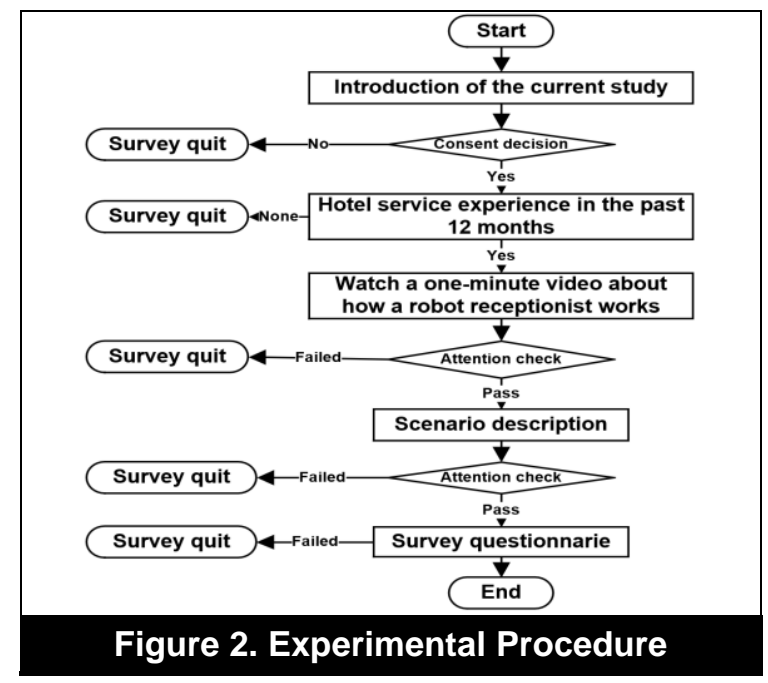

This study screened the collected responses and discarded unmindful responses that provided almost the same answer for each question, and those with a responding time less than 150 seconds. Finally, 95 responses for each scenario were obtained, amounting to a final sample size of 190 . Table 1 presents the respondents' demography.

\begin{tabular}{|c|c|c|c|}
\hline \multirow{2}{*}{ Variables } & \multirow{2}{*}{ Categories } & \multicolumn{2}{|c|}{ Count } \\
\hline & & S I & S II \\
\hline \multirow{2}{*}{ Gender } & Male & 64 & 57 \\
\hline & Female & 31 & 38 \\
\hline \multirow[t]{6}{*}{ Age } & $18-25$ years old & 3 & 6 \\
\hline & 26-35 years old & 47 & 41 \\
\hline & $36-45$ years old & 23 & 33 \\
\hline & $46-55$ years old & 17 & 7 \\
\hline & $56-65$ years old & 5 & 6 \\
\hline & 66 years old \& above & 0 & 2 \\
\hline \multirow[t]{6}{*}{ Education } & Less than high school & 1 & 0 \\
\hline & High school & 20 & 17 \\
\hline & Bachelor's degree & 59 & 58 \\
\hline & Master's degree & 11 & 17 \\
\hline & Ph.D. & 4 & 1 \\
\hline & Trade school & 0 & 2 \\
\hline \multirow[t]{2}{*}{ Marital status } & Yes & 50 & 41 \\
\hline & No & 45 & 54 \\
\hline \multirow{2}{*}{$\begin{array}{l}\text { Child-bearing } \\
\text { status }\end{array}$} & Yes & 55 & 58 \\
\hline & No & 40 & 37 \\
\hline \multirow[t]{5}{*}{ House income } & Less than $\$ 25,000$ & 10 & 10 \\
\hline & $\$ 25,000-50,000$ & 31 & 37 \\
\hline & $\$ 50,000-\$ 100,000$ & 38 & 35 \\
\hline & $\$ 100,000-\$ 200,000$ & 15 & 11 \\
\hline & More than $\$ 200,000$ & 1 & 2 \\
\hline
\end{tabular}

Note: SI means Scenario I; SII means Scenario II.

\section{Data Analysis}

This study utilizes the structural equation modeling (SEM) technique via SmartPLS 3.3 to test the proposed hypotheses. The SEM technique enables us to analyze both measurement and structural models [56]. Following the recommended procedure [57], the measurement model was first tested. After ensuring that all the constructs achieved adequate parameters for the path test, the structural model was tested.

\subsection{Test of the measurement model}

To verify the measurement model, we estimated the internal consistency and (convergent and discriminant) validity of the measurement items covered in our survey instrument. Since the reflective item captures the influence of the construct under scrutiny [58], we can assess internal consistency via three indictors: Cronbach's alpha, composite reliability 
(CR), and average variance extracted (AVE) [59]. Table 2 suggests an adequate level of internal consistency [60]. Further, convergent and discriminant validity of the measurement items were evaluated. All the factor loadings of the latent constructs exceed prescribed thresholds of 0.7 , showing good convergent validity [59]. For discriminant validity, the AVE's square root for each construct was compared against its correlations with other constructs [59]. To gain sufficient discriminant validity, the AVE's square root for every construct should be higher than any relevant bivariable correlations. The correlation matrix in Table 3 displays adequate discriminant validity. Since each bivariable correlation among the five latent constructs in our measurement model is much lower than corresponding AVE's square root, respondents can differentiate among the constructs in the theoretical model while filling in the questionnaire. In addition, individual items loadings beyond 0.5 on their associated factors further confirm both convergent and discriminant validity.

\begin{tabular}{|c|c|c|c|c|}
\hline \multicolumn{5}{|c|}{ Table 2. Internal Consistency and Validity } \\
\hline & $\begin{array}{c}\text { Minimal fac- } \\
\text { tor-loading }\end{array}$ & $\begin{array}{c}\text { Cronbach's } \\
\text { Alpha }\end{array}$ & CR & AVE \\
\hline $\mathrm{PR}$ & 0.942 & 0.964 & 0.974 & 0.904 \\
\hline $\mathrm{PI}$ & 0.804 & 0.922 & 0.941 & 0.801 \\
\hline $\mathrm{RI}$ & 0.957 & 0.975 & 0.981 & 0.930 \\
\hline $\mathrm{SH}$ & 0.809 & 0.951 & 0.958 & 0.743 \\
\hline
\end{tabular}

Notes: PR = Perceived risk; PI = Personal innovativeness; $\mathrm{RI}=$ Revisit intention; $\mathrm{SH}=$ Service heterogeneity. Criteria:Cronbach's alpha > 0.70; $\mathrm{CR}>0.70 ; \mathrm{AVE}>0.50$ [60].

\begin{tabular}{|c|c|c|c|c|c|}
\hline \multicolumn{7}{|c|}{ Table 3. Correlations } \\
\cline { 1 - 5 } & PR & PI & RI & SC & SH \\
\hline PR & $\mathbf{0 . 9 5 1}$ & \multicolumn{4}{|c|}{} \\
\hline Pl & -0.203 & $\mathbf{0 . 8 9 5}$ & \multicolumn{1}{|}{} \\
\hline RI & -0.652 & 0.325 & $\mathbf{0 . 9 6 4}$ & & \\
\hline SC & -0.673 & 0.199 & 0.676 & $\mathbf{1 . 0 0 0}$ & \\
\hline SH & 0.391 & 0.081 & 0.018 & -0.204 & $\mathbf{0 . 8 6 2}$ \\
\hline
\end{tabular}

Notes: PR $=$ Perceived risk; PI $=$ Personal innovativeness $\mathrm{RI}=$ Revisit intention; $\mathrm{SC}=$ Service context $\mathrm{SH}=$ Service heterogeneity. The bold number on the diagonal line represents the square root of AVE.

Variance inflation factors (VIF) values were computed to detect possible multicollinearity among the dependent and independent variables. All the VIF values are below the vigilance threshold of 5.0 [60]. Thus, multicollinearity is unlikely an issue for the proposed research model.

\subsection{Test of the structural model}

The structural model test involves estimating path coefficients, which indicate the power of the associations between the independent and dependent variables, and $R^{2}$ values, which indicate the amount of variance for the dependent variables explained by the independent variables. Taken together, the path coefficients (including both correlations and the significant level) and $R^{2}$ values demonstrate how well the data substantiate the hypothesized model.

Table 4 presents the results from the structural model analysis and substantiates all the hypothesized relationships. As postulated, customers' personal innovativeness negatively impacts perceived risk ( $\beta=$ -0.104; $p<0.05$ ), supporting H1. Customers' perceived service heterogeneity contributes to increased perceived risk ( $\beta=0.279 ; p<0.001$ ), confirming $H 2$. Personal innovativeness, together with service heterogeneity, explains $60.4 \%$ of the variance in perceived risk. Perceived risk, in turn, negatively influences service revisit intention $(\beta=-0.360 ; p<0.001)$, explaining $58.4 \%$ of the variance in the revisit intention and consistent with $H 3$.

To further test the mediating effects of perceived risk, we employ the approach prescribed by Nitzl et al. [61]. The first step is to verify the significance of the specific indirect relationship via the mediator. A significant result prompts the second step, which proceeds to test the direct relationship between the independent and dependent variables. If the direct relationship is insignificant, a full mediation can be concluded; otherwise, it is a partial mediation. As presented in Table 5, both specific indirect effects through the mediator are significant (PI: $\beta=0.045, p$ $<0.05$; SH: $\beta=-0.126, p<0.01)$. Further, either personal innovativeness in robotic service $(\beta=0.133, p$ $<0.01)$ or service heterogeneity $(\beta=0.227, p<0.001)$ has a significant direct negative influence on revisit intention. As a result, we can conclude that perceived risk partially mediates both the effects of personal innovativeness and service heterogeneity on service revisit intention.

Table 5. Results of Mediation Analysis
\begin{tabular}{|c|c|c|c|}
\hline IV & IV $\rightarrow$ DV & IV $\rightarrow$ M $\rightarrow$ DV & Mediation \\
\hline PI & $0.133^{* *}$ & $0.045^{*}$ & Partial \\
\hline SH & $0.227^{* * *}$ & $-0.126^{* *}$ & Partial \\
\hline
\end{tabular}

Notes: IV = Independent variable; $\mathrm{M}=$ Mediator; $\mathrm{DV}=$ Dependent variable. PI $=$ Personal innovativeness; $\mathrm{SH}=$ Service heterogeneity. ${ }^{*}$ correlation is significant at $0.05 ;{ }^{* *}$ correlation is significant at $0.01 ;{ }^{* * *}$ correlation is significant at 0.001 .

Service context works significantly as a moderator in the relationship between personal innovative- 
ness in robotic service and perceived risk $(\beta=-0.113$; $p<0.05$ ), therefore supporting $H 4$. Specifically, the service context where a service robot worked well and satisfied the customer can strengthen the negative effect of personal innovativeness in robotic service on perceived risk. The relationship between service heterogeneity and perceived risk is also significantly moderated by whether the previous experience is satisfying ( $\beta=0.271, p<0.001$ ), supporting $H 5$. That is to say, the situation where the prior service experience satisfied customers can strengthen the positive effect of service heterogeneity on perceived risk.

\begin{tabular}{|c|c|c|c|}
\hline Effects & Estimate & t-vaue & Hypotheses test \\
\hline \multicolumn{4}{|l|}{ Main effects } \\
\hline Personal innovativeness $\rightarrow$ Perceived risk & $-0.104^{*}$ & 4.607 & Supporting $H 1$ \\
\hline Service heterogeneity $\rightarrow$ Perceived risk & $0.279^{* * *}$ & 4.344 & Supporting $H 2$ \\
\hline Perceived risk $\rightarrow$ Revisit intention & $-0.360^{* * *}$ & 6.258 & Supporting $H 3$ \\
\hline \multicolumn{4}{|l|}{ Interaction effects } \\
\hline Personal innovativeness * service context $\rightarrow$ Perceived risk & $-0.113^{*}$ & 2.450 & Supporting $\mathrm{H} 4$ \\
\hline Service heterogeneity * service context $\rightarrow$ Perceived risk & $0.271^{* * *}$ & 4.769 & Supporting $H 5$ \\
\hline \multicolumn{4}{|l|}{ Control effects } \\
\hline House income $\rightarrow$ Revisit intention & $-0.158^{*}$ & 3.281 & \\
\hline Marital status $\rightarrow$ Revisit intention & $0.167^{* *}$ & 2.820 & \\
\hline Child-bearing status $\rightarrow$ Revisit intention & $0.001^{\mathrm{n} . \mathrm{s}}$ & 0.016 & \\
\hline Gender $\rightarrow$ Revisit intention & $0.056^{\text {n.s }}$ & 1.086 & \\
\hline Age $\rightarrow$ Revisit intention & $-0.103^{*}$ & 1.968 & \\
\hline Education $\rightarrow$ Revisit intention & $0.028^{\text {n.s. }}$ & 0.597 & \\
\hline Service context $\rightarrow$ Perceived risk & $-0.596^{* * *}$ & 11.683 & \\
\hline Service context $\rightarrow$ Personal innovativeness & $0.197^{* *}$ & 2.990 & \\
\hline Service context $\rightarrow$ Revisit intention & $0.447^{* *}$ & 7.339 & \\
\hline Service context $\rightarrow$ service heterogeneity & $-0.204^{* *}$ & 3.007 & \\
\hline
\end{tabular}

Notes: ${ }^{*}$ correlation is significant at $0.05 ;{ }^{* *}$ correlation is significant at $0.01 ;{ }^{* * * *}$ correlation is significant at $0.001 ;{ }^{\text {n.s. }}$ correlation is not significant at 0.05 .

\section{Discussion and Implications}

\subsection{Interpretation of major results}

Based on the major results of our research model, this study can help comprehensively understand customers' responding process to robotic service by explicating the roles of both customer trait and service characteristic in robotic service adoption.

First, personal innovativeness is negatively associated with customers' perceived risk in robotic service, leading to higher service revisit intention. This finding echoes previous studies that customer innovativeness plays a vital role in novel technology adoption and is critical for reducing customers' risk perception [19], [38]. Personal innovativeness reflects one's willingness to embrace innovations and ability to cope with uncertainties [36], [37]. Drawing from URT, it is feasible to mitigate customers' perceived risk in robotic service by promoting their innovativeness in robotic technologies.

Second, service heterogeneity is positively linked to customers' perceived risk, reducing their revisit intention to robotic service. Greater service heterogeneity indicates a higher possibility for the customer to receive discrepant services, equating to increased service performance uncertainty [25]. Such uncertainty can trigger customers' risk perception [26]. Our findings support the conclusion of AgudoPeregrina et al. [28] that homogeneous service can decrease customers' perceived risk and further increase their purchase intention.

The mediation analysis manifests that perceived risk partially mediates the relationship between personal innovativeness/service heterogeneity and service revisit intention. In addition to the direct impacts of both personal innovativeness and service heterogeneity on service revisit intention, there also exist indirect effects through the mediator of perceived risk. Specifically, improving personal innovativeness can eventually boost customers' revisit intention as it can reduce service uncertainty and perceived risk through increasing personal risk-taking competence. Meanwhile, reducing service heterogeneity can ultimately improve customers' revisit intention since it decreases the possibility that customers receive differing services. These instrumental findings highlight the role of customers' perceived risk and indicate that decreasing customers' risk perception from the perspec- 
tive of either customer or service characteristic has the potential to benefit service revisits.

Furthermore, the service context acts as a moderator in the relationship between personal innovativeness/service heterogeneity and perceived risk. Our results offer evidence that prior satisfying service alleviates the sense of risk in the next service visit. The satisfying service context can strengthen both the alleviating effect of personal innovativeness and the positive effect of service heterogeneity on risk perception.

\subsection{Theoretical and practical implications}

This study offers several implications on the theoretical front. First, despite that the dominant technology acceptance models provide insights into the formation of adoption intention [16], [17], this study contributes to further the understanding of robotic service adoption by clarifying the roles of both customer and service characteristics in AI technology adoption. Notably, identifying the critical service characteristic, i.e., service heterogeneity, conduces to a powerful instrument for future research that employs service heterogeneity as a theoretical lens to investigate robotic service. This study also enriches the existing literature and facilitates future empirical studies by systematically developing and verifying service heterogeneity measurements. While numerous researchers in the service science suggest that heterogeneity in service leads to adverse influences on customers' satisfaction yet without empirical support [62], [63], this study empirically shows that service heterogeneity significantly affects customers' service revisit intention directly and indirectly through the partial mediator of perceived risk.

Second, this study is among the first to employ URT to explain how customers respond to and adopt robotic service. Although past studies have confirmed the significance of personal innovativeness in technology adoption [18], [19] and argued negative implications of service heterogeneity on customer experience [10], this study focuses more on the mediating effect of perceived risk in the relationship between individual innovativeness/service heterogeneity and customers' revisit intention. Conceptualizing both customer and service characteristics, perceived risk, and service revisit intention within the URT framework offers a sharper theoretical lens to understand the mechanism of robotic service adoption.

The third contribution of our study is extending personal innovativeness and service heterogeneity by delineating the service context's influence. Specifically, the suppression of customers' risk perception by personal innovativeness can be strengthened in the satisfying service context. More importantly, this study empirically shows that the effect of service heterogeneity on customers' perceived risk differs after experiencing a satisfying as opposed to dissatisfying service. Our findings emphasize the importance of customers' initial interaction experience with service robots.

This study also conveys several practical implications. First, with robot attendants springing up into the service realm, practitioners need to realize the significance of promoting customers' innovativeness in increasing service revisits. Second, on the operational side of service robots, more attention should be paid to decreasing customers' risk perception and chewing over uncertainty reduction strategies. Third, service operators need to recognize the importance of simultaneously improving customers' initial experience with service robots and reducing robotic service heterogeneity.

Limitations still exist in the current study, which warrants further investigation. First, considering that this study utilized a scenario-based experiment with manipulated service contexts, a prospective study in the real-world setting is recommended to supply this research domain. Second, our study focused on customer trait, service characteristic, and perceived risk, a more comprehensive investigation is needed to address other constructs, such as comfort with robots and trust in robotic service.

\section{References}

[1] H. Osawa et al., "What is real risk and benefit on work with robots?: From the analysis of a robot hotel," in ACM/IEEE International Conference on HumanRobot Interaction, 2017, pp. 241-242.

[2] J. Murphy, C. Hofacker, and U. Gretzel, "Dawning of the age of robots in hospitality and tourism: Challenges for teaching and research," Eur. J. Tour. Res., vol. 15, pp. 104-111, 2017.

[3] I. P. Tussyadiaha and S. Parkb, "Consumer Evaluation of Hotel Service Robots," in Information and Communication Technologies in Tourism 2018, B. Stangl and J. Pesonen, Eds. Springer International Publishing, 2018, pp. 308-320.

[4] C. R. BERGER and R. J. CALABRESE, "Some explorations in initial interaction and beyond: Toward a developmental theory of interpersonal communication," Hum. Commun. Res., vol. 1, no. 2, pp. 99-112, 1975.

[5] H. Sun, R. T. Wright, and J. B. Thatcher, "Revisiting the impact of system use on task performance: an exploitative-explorative system use framework," $J$. Assoc. Inf. Syst., vol. 20, no. 4, pp. 398-433, 2019.

[6] J. B. Thatcher and P. L. Perrewé, "An Empirical Examination of Individual Traits as Antecedents to Computer Anxiety and Computer Self-Efficacy," MIS 
$Q .$, vol. 26, no. 4, pp. 381-396, 2002.

[7] A. V. Citrin, D. E. Sprott, S. N. Silverman, and D. E. Stem, "Adoption of Internet shopping: The role of consumer innovativeness," Ind. Manag. Data Syst., vol. 100, no. 7, pp. 294-300, 2000.

[8] M. Kim, J. Song, and J. Triche, "Toward an integrated framework for innovation in service: A resource-based view and dynamic capabilities approach," Inf. Syst. Front., vol. 17, no. 3, pp. 533-546, 2015.

[9] L. Pitt, P. Berthon, and R. T. Watson, "Cyberservice: Taming service marketing problems with the world wide web," Bus. Horiz., vol. 42, no. 1, pp. 11-18, 1999.

[10] S. Roy and K. Sivakumar, "Which controls are better for service outsourcing? Integrating service-dominant logic and service characteristics," AMS Rev., vol. 4, no. 3-4, pp. 45-62, 2014.

[11] B. R. Kinard and M. L. Capella, "Relationship marketing: The influence of consumer involvement on perceived service benefits," J. Serv. Mark., vol. 20, no. 6, pp. 359-368, 2006.

[12] C. Y. Shao, J. A. Baker, and J. A. Wagner, "The effects of appropriateness of service contact personnel dress on customer expectations of service quality and purchase intention: The moderating influences of involvement and gender," J. Bus. Res., vol. 57, no. 10, pp. 1164-1176, Oct. 2004.

[13] A. Lievens and R. K. Moenaert, "Project Team Communication in Financial Service Innovation," J. Manag. Stud., vol. 37, no. 5, pp. 733-766, 2000.

[14] O. William, E. E. Appiah, and E. A. Botchway, "Assessment of customer expectation and perception of service quality delivery in Ghana Commercial Bank," J. Humanit., vol. 4, no. 1, pp. 81-91, 2016.

[15] D. F. Midgley and G. R. Dowling, "Innovativeness: The Concept and Its Measurement," J. Consum. Res., vol. 4, no. 4, p. 229, 1978.

[16] E. M. Rogers, "Diffusion of preventive innovations," in Addictive Behaviors, 2002, vol. 27, no. 6, pp. 989993.

[17] R. Agarwal and J. Prasad, "A Conceptual and Operational Definition of Personal Innovativeness in the Domain of Information Technology," Inf. Syst. Res., vol. 9, no. 2, pp. 204-215, 1998.

[18] C. W. Chao, M. Reid, and F. Mavondo, "Global consumer innovativeness and consumer electronic product adoption," Asia Pacific J. Mark. Logist., vol. 25, no. 4, pp. 614-630, 2013.

[19] V. Chauhan, R. Yadav, and V. Choudhary, "Analyzing the impact of consumer innovativeness and perceived risk in internet banking adoption: A study of Indian consumers," Int. J. Bank Mark., vol. 37, no. 1, pp. 323-339, 2019.

[20] S. Im, C. H. Mason, and M. B. Houston, "Does innate consumer innovativeness relate to new product/service adoption behavior? the intervening role of social learning via vicarious innovativeness," J. Acad. Mark. Sci., vol. 35, no. 1, pp. 63-75, 2007.

[21] R. Thakur and M. Srivastava, "A study on the impact of consumer risk perception and innovativeness on online shopping in India," Int. J. Retail Distrib.
Manag., vol. 43, no. 2, pp. 148-166, 2015.

[22] A. A. Akaso, "Building Competitive and Sustainable Strategies for Improving Quality of Service Delivery in Maritime Academic of Nigeria, Oron," Int. J. Econ. Dev. Res. Invest., vol. 2, no. 2, pp. 122-128, 2011.

[23] V. A. Zeithaml, A. Parasuraman, and L. L. Berry, "Problems and Strategies in Services Marketing," $J$. Mark., vol. 49, no. 2, p. 33, 1985.

[24] L. L. Berry, "Perspectives on the retailing of services," in Theory in Retailing: Traditional and Nontraditional Sources, R. W. Stampfl and E. Hirschman, Eds. 1981, pp. 9-20.

[25] S. Onkvisit and J. J. Shaw, "Marketing theories, models and general issues: Is services marketing 'really'different?," J. Prof. Serv. Mark., vol. 7, no. 2, pp. 3-17, Nov. 1991.

[26] K. M. Thompson, "Variability and uncertainty meet risk management and risk communication," Risk Anal., vol. 22, no. 3, pp. 647-654, Jun. 2002.

[27] H. Dabrynin and J. Zhang, "The Investigation of the Online Customer Experience and Perceived Risk on Purchase Intention in China," J. Mark. Dev. Compet., vol. 13, no. 2, 2019.

[28] Á. F. Agudo-Peregrina, F. J. Pascual-Miguel, and J. Chaparro-Peláez, "It's never the same: The role of homogeneity in online services," Serv. Bus., vol. 8, no. 3, pp. 453-464, 2014.

[29] C. R. Berger, "Beyond initial interaction: Uncertainty, understanding, and the development of interpersonal relationships," in Language and social psychology, 1979, pp. 122-144.

[30] M. L. Antheunis, P. M. Valkenburg, and J. Peter, "Getting acquainted through social network sites: Testing a model of online uncertainty reduction and social attraction," Comput. Human Behav., vol. 26, pp. 100-109, 2010.

[31] S. Il Shin, K. Y. Lee, and S. B. Yang, "How do uncertainty reduction strategies influence social networking site fan page visiting? Examining the role of uncertainty reduction strategies, loyalty and satisfaction in continuous visiting behavior," Telemat. Informatics, vol. 34, no. 5, pp. 449-462, Aug. 2017.

[32] V. Venkatesh, J. Y. L. Thong, F. K. Y. Chan, and P. J. $\mathrm{H}$. $\mathrm{Hu}$, 'Managing citizens' uncertainty in egovernment services: The mediating and moderating roles of transparency and trust," Inf. Syst. Res., vol. 27, no. 1, pp. 87-111, 2016.

[33] P. Racherla, M. Mandviwalla, and D. J. Connolly, "Factors affecting consumers' trust in online product reviews," J. Consum. Behav., vol. 11, no. 2, pp. 94104, Mar. 2012.

[34] K. B. Murray, "A Test of Services Marketing Theory: Consumer Information Acquisition Activities," $J$. Mark., vol. 55, no. 1, pp. 10-25, 1991.

[35] T. Daugherty, H. Li, and F. Biocca, "Consumer learning and the effects of virtual experience relative to indirect and direct product experience," Psychol. Mark., vol. 25, no. 7, pp. 568-586, Jul. 2008.

[36] E. M. Rogers, Diffusion of Innovations, 4th Edition. New York Press, 1995.

[37] D. F. Cox and S. U. Rich, "Perceived Risk and 
Consumer Decision-Making: The Case of Telephone Shopping," J. Mark. Res., vol. 1, no. 4, p. 32, 1964.

[38] J. Aldás-Manzano, C. Lassala-Navarré, C. Ruiz-Mafé, and S. Sanz-Blas, "The role of consumer innovativeness and perceived risk in online banking usage," Int. J. Bank Mark., vol. 27, no. 1, pp. 53-75, 2009.

[39] S. Manohar and V. Rehman, "Do People Rely on Information for Food Choice?: The Role of the Type of Novelty and Personality Traits," in European Advances in Consumer Research, vol. 11, Association for Consumer Research, 2019, pp. 71-71.

[40] G. R. Dowling, "Perceived risk: The concept and its measurement," Psychol. Mark., vol. 3, no. 3, pp. 193210, Sep. 1986.

[41] M. A. Baker, "Service failure and recovery: theories and models," in Service failures and recovery in tourism and hospitality: a practical manual, E. Koc, Ed. 2017, pp. 27-41.

[42] L. H. Kim, D. J. Kim, and J. K. Leong, "The effect of perceived risk on purchase intention in purchasing airline tickets online," J. Hosp. Leis. Mark., vol. 13, no. 2, pp. 33-53, 2005.

[43] V. S. Folkes, "How Consumers Predict Service Quality: What do they Expect?," in The service quality handbook, E. E. E. S. \& W. F. Christopher, Ed. New York: American Management Association, 1993, pp. 108-123.

[44] J. Casper, "Sport Commitment, Participation Frequency and Purchase Intention Segmentation based on Age, Gender, Income and Skill Level with US Tennis Participants," Eur. Sport Manag. Q., vol. 7, no. 3, pp. 269-282, 2007.

[45] A. Vance, P. B. Lowry, and D. Eggett, "Increasing accountability through user-interface design artifacts: A new approach to addressing the problem of accesspolicy violations," $M I S Q$., vol. 39, no. 2, pp. 345-366, 2015.

[46] N. K. Malhotra, S. S. Kim, and J. Agarwal, "Internet users' information privacy concerns (IUIPC): The construct, the scale, and a causal model," Inf. Syst. Res., vol. 15, no. 4, pp. 336-355, 2004.

[47] H. Sheng, F. Nah, and K. Siau, "An experimental study on U-commerce adoption: The impact of personalization and privacy concerns," in Association for Information Systems, 2008, vol. 9, no. 6, pp. 344376.

[48] D. Straub, M.-C. Boudreau, and D. Gefen, "Validation Guidelines for IS Positivist Research," Commun. Assoc. Inf. Syst., vol. 13, pp. 380-427, 2004.

[49] W. Lauder, "Factorial survey methods: A valuable but under-utilised research method in nursing research?," Nurs. Times Res., vol. 7, no. 1, pp. 35-43, 2002.

[50] G. C. Moore and I. Benbasat, "Development of an Instrument to Measure the Perceptions of Adopting an Information Technology Innovation," Inf. Syst. Res., vol. 2, no. 3, pp. 192-222, 1991.

[51] H. Sun, "Understanding user revisions when using information system features: Adaptive system use and triggers," MIS Q., vol. 36, no. 2, pp. 453-478, 2012.

[52] H. H. Mcknight, V. Choudhury, and C. Kacmar,
"Developing and Validating Trust Measures for eCommerce: An Integrative Typology," Inf. Syst. Res., vol. 13, no. 3, 2002.

[53] B. J. Corbitt, T. Thanasankit, and H. Yi, "Trust and ecommerce: A study of consumer perceptions," Electron. Commer. Res. Appl., vol. 2, no. 3, pp. 203215, 2003.

[54] J. Sun, "How risky are services? An empirical investigation on the antecedents and consequences of perceived risk for hotel service," Int. J. Hosp. Manag., vol. 37, pp. 171-179, Feb. 2014.

[55] H. Van der Heijden and T. Verhagen, "Online store image: Conceptual foundations and empirical measurement," Inf. Manag., vol. 41, no. 5, pp. 609617, 2004.

[56] Chin, Marcolin, and Newsted, "A partial least squares latent variable modeling approach for measuring interaction effects: results from a monte carlo simulation study and an electronic-mail emotion/adoption study," Inf. Syst. Res., vol. 14, no. 2, pp. 189-217, 2003.

[57] J. Hulland, "Use of partial least squares (pls) in strategic management research: a review of four recent studies," Strateg. Manag. J., vol. 20, no. 2, pp. 195204, 2015.

[58] L. T. Hu and P. M. Bentler, "Cutoff criteria for fit indexes in covariance structure analysis: Conventional criteria versus new alternatives," Struct. Equ. Model. A Multidiscip. J., vol. 6, no. 1, pp. 1-55, 1999.

[59] C. Fornell and D. F. Larcker, "Evaluating structural equation models with unobservable variables and measurement error," J. Mark. Res., vol. 18, no. 1, pp. 39-50, 1981.

[60] J. F. Hair, R. E. Anderson, R. L. Tatham, and W. C. Black, Multivariate data analysis with readings (5nd ed.). 1998.

[61] C. Nitzl, J. L. Roldan, and G. Cepeda, "Mediation analysis in partial least squares path modelling, Helping researchers discuss more sophisticated models," Ind. Manag. Data Syst., vol. 116, no. 9, pp. 1849-1864, 2016.

[62] G. Pires and J. Stanton, "Marketing services aross cultures," in Cross-Cultural Marketing, 2003, pp. 182-208.

[63] Y. Ding and H. T. Keh, "A re-examination of service standardization versus customization from the consumer's perspective," J. Serv. Mark., vol. 30, no. 1, pp. 16-28, 2016. 